\title{
Plasma evolution and dynamics in high-power vacuum-transmission-line post-hole convolutes
}

\author{
D. V. Rose, ${ }^{*}$ D. R. Welch, T. P. Hughes, and R. E. Clark \\ Voss Scientific, LLC, Albuquerque, New Mexico 87108, USA \\ W. A. Stygar \\ Sandia National Laboratories, Albuquerque, New Mexico 87185, USA
}

(Received 11 February 2008; published 6 June 2008)

\begin{abstract}
Vacuum-post-hole convolutes are used in pulsed high-power generators to join several magnetically insulated transmission lines (MITL) in parallel. Such convolutes add the output currents of the MITLs, and deliver the combined current to a single MITL that, in turn, delivers the current to a load. Magnetic insulation of electron flow, established upstream of the convolute region, is lost at the convolute due to symmetry breaking and the formation of magnetic nulls, resulting in some current losses. At very highpower operating levels and long pulse durations, the expansion of electrode plasmas into the MITL of such devices is considered likely. This work examines the evolution and dynamics of cathode plasmas in the double-post-hole convolutes used on the $Z$ accelerator [R. B. Spielman et al., Phys. Plasmas 5, 2105 (1998)]. Three-dimensional particle-in-cell (PIC) simulations that model the entire radial extent of the $Z$ accelerator convolute - from the parallel-plate transmission-line power feeds to the $z$-pinch load regionare used to determine electron losses in the convolute. The results of the simulations demonstrate that significant current losses (1.5 MA out of a total system current of 18.5 MA), which are comparable to the losses observed experimentally, could be caused by the expansion of cathode plasmas in the convolute regions.
\end{abstract}

DOI: 10.1103/PhysRevSTAB.11.060401

PACS numbers: $84.70 .+\mathrm{p}, 52.58 . \mathrm{Lq}, 52.65 . \mathrm{Rr}$

\section{INTRODUCTION}

Vacuum post-hole convolutes [1-5] are a critical component in present [6] and future high-power $z$-pinch drivers [7,8]. A post-hole convolute is used to join several magnetically insulated transmission lines (MITL) in parallel, transferring the combined currents to a single transmission line that drives a dynamic $z$-pinch load. Magnetic insulation is lost at positions inside the convolute due in part to symmetry breaking and the formation of magnetic field nulls. These nulls arise from the splitting of the radially converging current that is forced to divide and flow around the holes. (See Refs. [1-4] for detailed discussions of the post-hole convolute current paths leading to formation of these nulls.)

Electron sheath current losses in the convolute region of vacuum transmission lines have been modeled previously [1-4] for the 50-TW $Z$ machine [9-13]. That modeling, however, accounts for only a small fraction of the current losses measured experimentally [14]. Furthermore, planned $z$-pinch facilities [7] will operate at even higher electrical powers. Therefore exploration of various mechanisms that can lead to the measured losses is of critical interest. In this article, we investigate through numerical simulation whether the formation and evolution of electrode plasmas in the vicinity of the holes explains the experimental observations. We present results of detailed modeling of electrode-plasma formation and evolution,

*David.Rose@vosssci.com and show that under a reasonable set of conditions, such plasmas could cause most of the observed current loss.

Direct observation of plasma evolution in post-hole convolutes is difficult due to limited lines of sight and other constraints, especially on $Z$. Experiments with coaxial MITLs, however, have been carried out to specifically measure the impact of electrode plasmas [15-19]. For example, at relevant current levels and voltages of order $1 \mathrm{MA}$ and $1 \mathrm{MV}$, plasma evolution from the cathode was observed on time scales of approximately $100 \mathrm{~ns}$, with densities of order $10^{16} \mathrm{~cm}^{-3}$ and temperatures of order $3 \mathrm{eV}[17,18]$. This experiment used coaxial MITLs with anode-cathode (AK) gaps of order $2 \mathrm{~mm}$ and carefully prepared (cleaned) electrode surfaces. Observations such as these provide some guidance and motivation for the modeling undertaken in this paper.

Here, three-dimensional particle-in-cell (PIC) simulations are used to study the dynamics of electrode plasmas in post-hole convolutes. The simulations use an explicit electromagnetic field solver, energy-conserving particle advance, and a new model for electrode-plasma creation to treat the formation and evolution of dense cathode plasmas [20] in high-power transmission lines. With this new capability, simulations of the $Z$ accelerator double post-hole (DPH) convolutes and load region that include electron emission as well as cathode and anode-plasma formation in the vicinity of the convolute are now feasible. Potential electrical power loss in this region due to the presence of these plasmas can be estimated for the first time. 


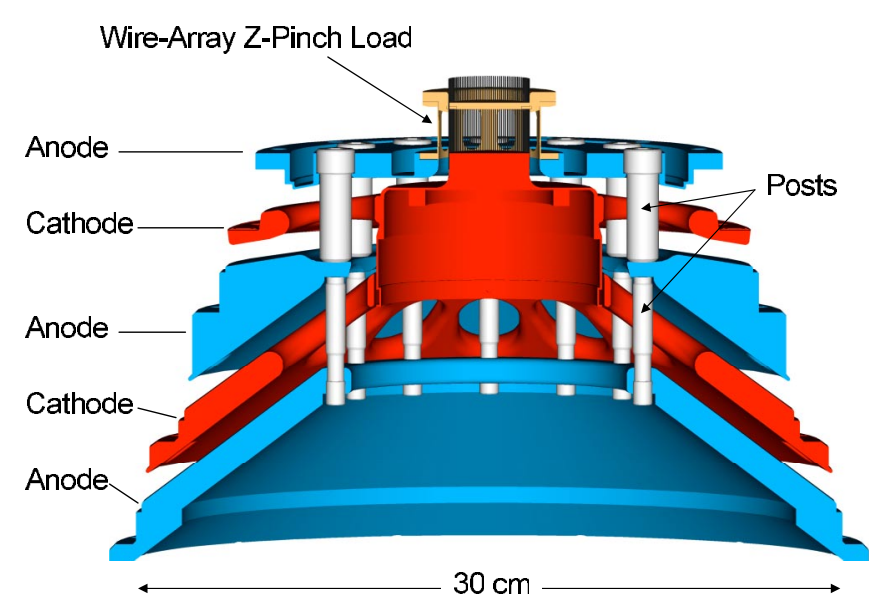

FIG. 1. (Color) Cutaway drawing of the $Z$ machine DPH convolute including a wire-array $z$-pinch load. Anode hardware is shown as blue and grey parts and cathode parts are shown in red.

A cutaway drawing of the $Z \mathrm{DPH}$ convolute is shown in Fig. 1. This figure illustrates the locations of the upper and lower level anode posts, the cathode and anode components of the MITLs, and the location of the wire-array $z$-pinch load. The system uses 24 posts (twelve upper and twelve lower) to provide the return current path connecting the inner anode to the outer anodes through holes in the cathode plates. After a typical dynamic load shot on $Z$, hardware damage is observed in four main locations: (D1) the posts, (D2) the horizontal anode surface between adjacent upper level posts, (D3) the vertical inner face of the lower post support, and (D4) on the inner MITL anode (these positions are indicated in Fig. 2 which gives two views of the simulation geometry and illustrates the addition of the current paths between the four MITLs and the load). Previous simulations [1-4] have shown significant electron energy deposition at all of these locations. The simulations presented here support these previous results and show, consistent with experimental observation, increased electron energy deposition at these locations when cathode plasma evolution is included.

This paper is organized as follows. In Sec. II, the simulation models used in this work are summarized. In Sec. III, a series of numerical simulations of the $Z$ DPH convolutes are presented for a $2-\mathrm{cm}$ radius load configuration using 6- $\Omega$ transmission-line driver sections. This particular configuration has been explored previously [1-4] using simulations that did not include electrode-plasma formation and evolution. The overall implications of these modeling results in terms of interpreting the existing $Z$ shot data base and the design of future accelerator architectures are discussed in Sec. IV.

\section{SIMULATION MODEL}

The PIC code LSP [21-24] is used in 3D $(r, \theta, z)$ to examine power flow losses in the vicinity of the $Z$ DPH

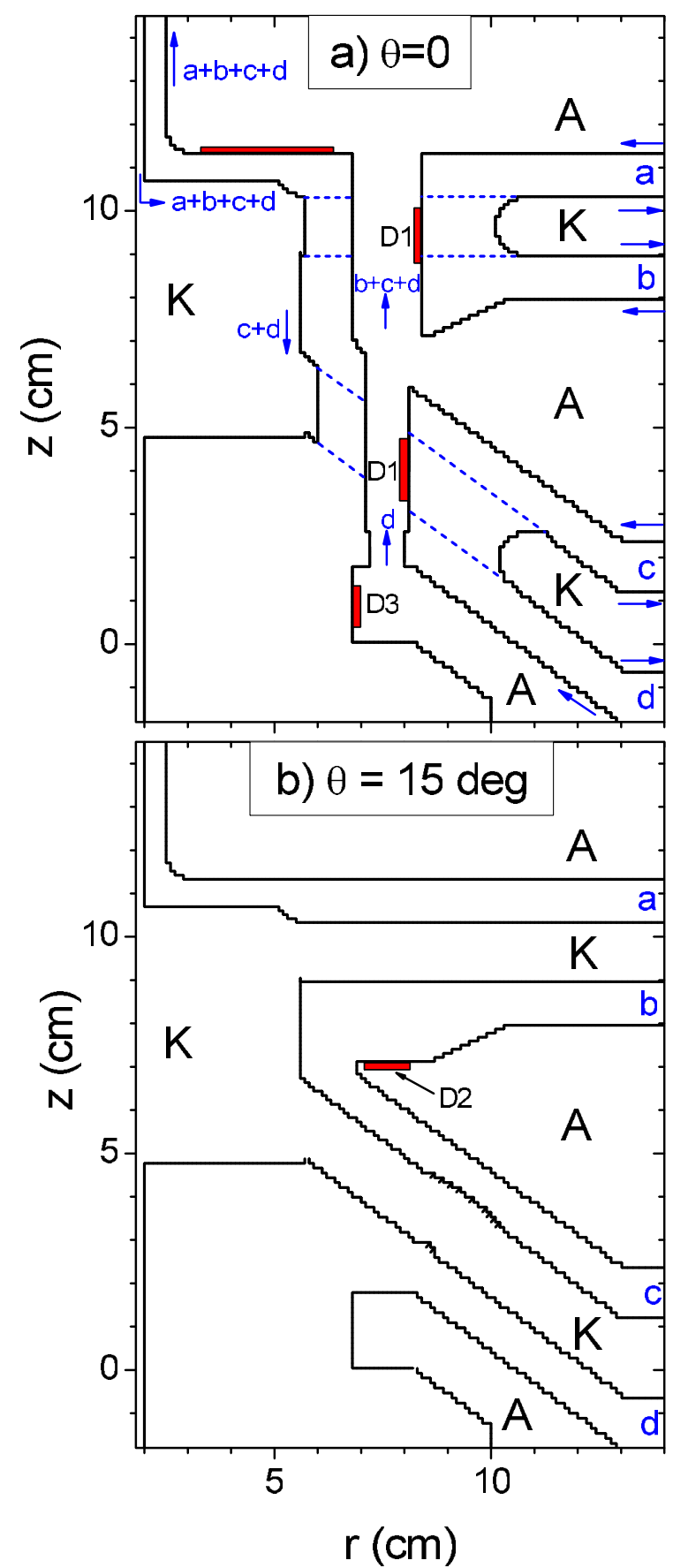

FIG. 2. (Color) Views of the simulation geometry for the 2-cm load simulations in the $\theta=0$ and 15-degree planes. Anode and cathode components are labeled " $\mathrm{A}$ " and " $\mathrm{K}$," respectively, and the lower case letters $(a-d)$ indicate the four input levels for the circuit drivers. The dashed blue lines in (a) indicate the connection of the cathode components outside of the $\theta=0$ plane. The current paths and summation are labeled with blue arrows and letters (after Fig. 2 of Pointon et al. [4]). The load model is attached at the outlet boundary at the top of each frame.

convolutes. The simulations are fully electromagnetic and use an energy-conserving cloud-in-cell model for the particles $[21,25]$ that avoids numerical heating associated with 
under-resolution of the plasma Debye length and helps minimize electrostatic fluctuations on the grid. Several different explicit and implicit electromagnetic field solvers are implemented within the LSP framework, and each has specific attributes that enable the examination of different time and spatial scale phenomena. After several test simulations, the combination of explicit electromagnetic field solver with the cloud-in-cell particle model was found to be the most efficient as well as numerically accurate and stable, with the time step $\Delta t$ set to be sufficiently small in order to resolve both electron-cyclotron $\left(\omega_{\mathrm{ce}}\right)$ and electronplasma $\left(\omega_{\text {pe }}\right)$ frequencies such that $\left(\omega_{\text {pe }}, \omega_{\text {ce }}\right) \Delta t<2$. The energy-conserving cloud-in-cell model has been successfully validated in conjunction with LSP electrostatic and electromagnetic field solvers to analyze several waveparticle and wave-wave interactions including $1 \mathrm{D}$ and 2D studies of streaming instabilities [26-29], Landau damping [30], and drift-cyclotron instabilities [31].

For the cases that include the creation and evolution of cathode plasmas, the simulations use three separate particle species to represent space-charge-limited (SCL) electron emission, neutral desorption from electrode surfaces and ions $\left(\mathrm{H}^{+}\right)$resulting from the ionization of the neutral particles. This scheme is part of a novel electrode-plasma model being developed [20]. A fourth particle species is included for cases where SCL ion emission is modeled from anode structures. In addition, a newly developed adaptive particle management scheme is used to help control the total number of macroparticles in the simulations [32], particularly for the cathode plasma injection simulations. The simulations presented here are carried out on large-scale parallel computer systems ${ }^{1}$ and are comprised of $\sim 1.3 \times 10^{6}$ cells, $1-3 \times 10^{7}$ macroparticles, and $1-3 \times 10^{6}$ time steps.

The cathode plasma formation model used here assumes the explosive emission of electrons and desorption of a neutral, thermal particle layer from a conducting surface at a prescribed rate. Electrons are emitted from cathode surfaces using a relativistically correct SCL model with an electric field threshold of $240 \mathrm{kV} / \mathrm{cm}$. This emission threshold is consistent with several published estimates for stainless steel and aluminum cathode materials (see, for example, Ref. [36]). The desorption is initiated on a cell-by-cell basis once the local electric field exceeds the threshold set for SCL emission, although other criteria can be specified. The neutral desorption rates, $D$, between $0.003-0.25 \mathrm{ml} / \mathrm{ns}$ are used, a typical range of contaminant desorption rates in pulsed-power vacuum operating environments $\left[1\right.$ monolayer $\left.(\mathrm{ml})=10^{15} \mathrm{~cm}^{-2}\right]$. These desorp-

\footnotetext{
${ }^{1}$ Between 60 and 120 processors of the Sandia National Laboratories (SNL) Thunderbird computer cluster were used for the largest plasma simulations. This computer system was designed and built by SNL and Dell [33]. It contains 8960 Intel [34] xeon processors operating at $3.6 \mathrm{GHz}$ and uses the Infiniband interconnect architecture [35].
}

tion rates are consistent with models of cathode plasma evolution [37] where the leading edge of the expanding plasma must be sufficiently dense to allow SCL emission of electrons. This, in turn, gives an ion current returning to the cathode from the plasma that is of order of the SCL current. In the model, desorbed neutral particles are ionized uniformly within the first cell adjacent to the conducting surface. This technique ensures charge conservation in the PIC simulation and prevents the formation of unphysical sheaths along the conducting surface. The plasma selfsimilarly expands under the influence of local electromagnetic fields. This relatively dense $\left(n_{p} \sim 10^{14}-10^{17} \mathrm{~cm}^{-3}\right)$ plasma can effectively act as a dynamic conducting boundary, with SCL emission of electrons occurring at the leading edge of the expanding plasma. Additionally, Coulomb scattering between all particles is treated in Monte Carlo fashion assuming the Spitzer collision frequency [21]. The dynamic mechanisms governing the self-similar expansion and evolution of these plasmas are described elsewhere [20,38].

The simulations use forward-traveling voltage waveforms feeding transmission-line circuits that are in turn attached to the PIC simulation grid (see the Appendix for details). Each simulation is terminated by a $2-\mathrm{cm}$ inner radius $\left(r_{L}\right)$ coaxial transmission line and this section is coupled to a 1D imploding liner model. The load model assumes a 2-cm initial inner radius, 2-cm-long shell of mass $4.09 \mathrm{mg}$ with a 20:1 aspect ratio for the implosion. This value is larger than the 10:1 aspect ratio typically obtained on $Z$ [14] and results in a delay in the time of peak power at the load relative to actual $Z$ measurements.

In addition to the cathode plasma injection model, most of the simulations discussed in Sec. III include a model for the SCL emission of ions from the anode posts. This ion emission mechanism is triggered by accumulated electron energy deposition resulting in a local surface temperature increase of $400^{\circ} \mathrm{C}$. This threshold condition is based on experimental evidence from high-power charged-particle diode research (see, for example, Refs. [39,40]). A fourth charged-particle species is used in these simulations to individually track the dynamics of these anode-emitted ions.

\section{SIMULATION RESULTS}

We summarize the results of new 3D PIC simulations of the $Z$ DPH convolute using a 2-cm radius load with a 5-mm AK gap region upstream of the load. The simulations in this section use 6- $\Omega$ drive circuits as described in the Appendix. Two views of the simulation geometry are shown in Fig. 2. To describe the 12 DPH convolutes in the $Z$ machine design, the simulation volume is periodic in $\theta$, extending between \pm 15 degrees. Slice-plane $(r, z)$ views at $\theta=0$ and 15 degrees are shown in the figure. The four power feed levels are indicated with lower case letters $(\mathrm{a}-\mathrm{d})$ and the anode $(\mathrm{A})$ and cathode $(\mathrm{K})$ parts 
TABLE I. Summary of 3D PIC simulations of the $Z$ DPH giving the approximate peak load current obtained and the approximate total anode current upstream of the convolute region.

\begin{tabular}{|c|c|c|c|}
\hline Case number and description & $\begin{array}{l}D, \text { the plasma } \\
\text { injection rate } \\
\quad(\mathrm{ml} / \mathrm{ns})\end{array}$ & $\begin{array}{c}I_{L}, \text { the peak } \\
\text { load current } \\
\text { (MA) }\end{array}$ & $\begin{array}{c}I_{A}, \text { the } \\
\text { upstream } \\
\text { anode current } \\
\text { (MA) }\end{array}$ \\
\hline 1. Cold test & $\cdots$ & 18.5 & 18.5 \\
\hline 2. Electron emission & $\cdots$ & 18.5 & 18.6 \\
\hline 3. Cathode plasma injection & 0.25 & 16.4 & 21.2 \\
\hline $\begin{array}{l}\text { 4A. Cathode plasma } \\
\text { injection with } \\
\text { ion emission } \\
\text { from anode posts }\end{array}$ & 0.25 & 15.0 & 21.9 \\
\hline 4B. & 0.125 & 16.0 & 22.2 \\
\hline $4 \mathrm{C}$. & 0.0625 & 16.3 & 21.2 \\
\hline 4D. & 0.03125 & 16.8 & 20.4 \\
\hline $4 \mathrm{E}$. & 0.015 & 17.4 & 20.2 \\
\hline $4 \mathrm{~F}$. & 0.0075 & 17.7 & 19.2 \\
\hline 4G. & 0.00325 & 18.3 & 18.9 \\
\hline
\end{tabular}

labeled. The load model is attached at the outlet boundary located at the top of each frame.

Four types of simulations have been carried out and these types are labeled "1" through " 4 " in Table I. The first type is a "cold test" in which the electromagnetic field solver is advanced without any particle creation, driving the load region as a purely vacuum wave device. The coldtest simulation gives a peak load current, shown in Fig. 3, of about 18.5 MA, consistent with measurements made

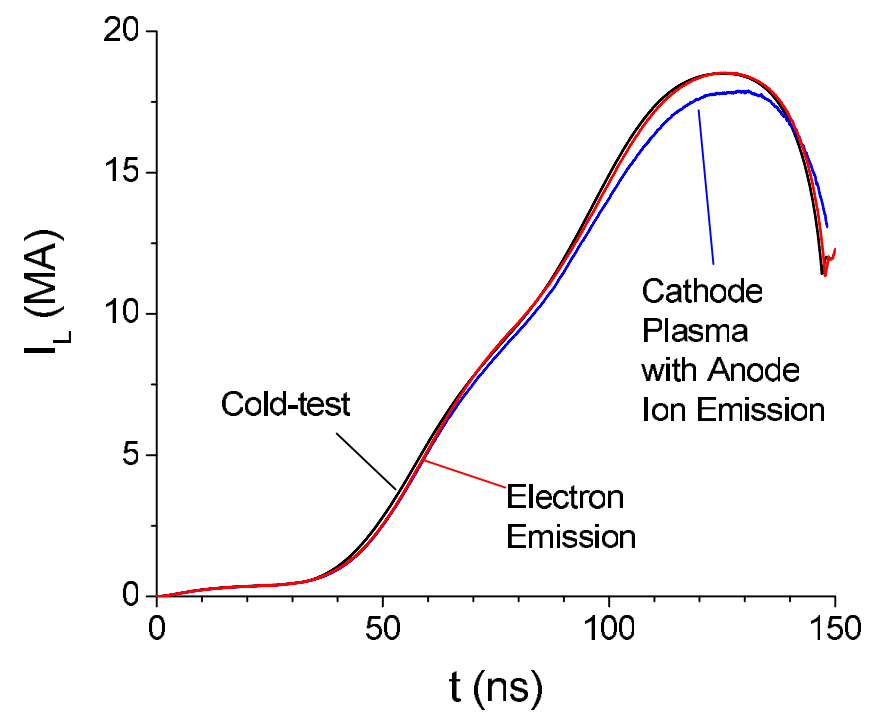

FIG. 3. (Color) Comparison of the simulated load currents as a function of time. The black curve represents the cold-test result, the red curve represents a simulation with electron emission from the cathode surfaces. The blue curve is the load current from a simulation that includes cathode plasma injection $(D=$ $0.0075 \mathrm{ml} / \mathrm{ns}$ ) and ion emission from the posts (case $4 \mathrm{~F}$ ). upstream of the load convolutes on $Z$ and with previous simulations.

The second simulation type allows SCL emission of electrons from cathode surfaces as done in previous work [1-4]. Current losses in the convolute region from this "electron-only" simulation are roughly $0.5 \%$, consistent with the previous analyses. Electron power flow losses have long been recognized as a potential issue for power delivery efficiency in vacuum post-hole convolute systems. Previous studies of the $Z$ DPH convolute have indicated that losses of order $100 \mathrm{kA}$ (out of $\sim 18.5 \mathrm{MA}$ of total current) result from the loss of magnetic insulation in the vicinity of the magnetic nulls [1-4]. These estimates are confirmed in simulations when the cold-test results are compared with simulations initiating electron emission from cathode surfaces. Figure 3 compares the cold-test load current with the load current from the electron emission simulation. At peak power, electron sheath currents flowing in the vicinity of the load are of order $70 \mathrm{kA}$, consistent with previous simulation results.

The third simulation type adds cathode plasma desorption in the vicinity of the holes in the convolute region. This plasma is liberated from the cathode surface once SCL emission is enabled (i.e., when the local electric field at the surface exceeds the threshold condition of $240 \mathrm{kV} / \mathrm{cm}$ ). The plasma (once transitioned from the injected neutral particles) is a fully ionized, electron-proton population with $10^{14}-10^{17} \mathrm{~cm}^{-3}$ number density at $\sim 3 \mathrm{eV}$ (consistent with available data in Refs. [17,18]). A single simulation is given in Table I for this case with a relatively high plasma desorption rate $(D=0.25 \mathrm{ml} / \mathrm{ns})$, demonstrating the dramatic loss of coupled load current that can result from cathode plasma desorption, independent of any anode effects. 
The fourth simulation type considered here adds spacecharge-limited emission of ions (protons) from the anode to the cathode plasma desorption case. It has long been recognized that many of the anode components of the DPH convolute are heated by bombardment of energetic electrons. Applying a SCL ion emission model to these anode components essentially models the formation of a very thin plasma layer at the anode surface from which ions can be accelerated. Although volumetric expansion of dense $\left(\geq 10^{17} \mathrm{~cm}^{-3}\right.$ ) anode plasmas is a possibility in the $Z$ DPH convolute, we do not attempt to explicitly model these significantly denser plasmas since they likely expand into the vacuum gaps at a much slower rate (of order $1 \mathrm{~cm} / \mu \mathrm{s})$ [41-43].

The plasma desorption rate for this fourth simulation type is varied between 0.00325 and $0.25 \mathrm{ml} / \mathrm{ns}$ (cases 4A$4 \mathrm{G}$ in Table I). We find that the plasma desorption rate strongly influences the amount of current that is coupled to the load. In concert with this change in coupled load current, the desorbed plasma dynamically modifies the inductance in the convolute region. The difference in the peak upstream (anode) current, $I_{A}$, and the peak load current, $I_{L}$, for each plasma injection case listed in Table I is defined as the "loss current" $\left(I_{A}-I_{L}\right)$ and this parameter is plotted in Fig. 4 as a function of the plasma desorption rate, $D$. The loss current is approximately logarithmic in $D$ as illustrated by the sample fit (dashed line) in Fig. 4 [the dashed line is approximately given by $8.96+$ $1.48 \ln (D)]$. We find that the typical loss current measured on the $Z$ machine of $\sim 1.5 \mathrm{MA}$ is reasonably approximated by the $D=0.0075 \mathrm{ml} / \mathrm{ns}$ simulation (case $4 \mathrm{~F}$ in Table I).

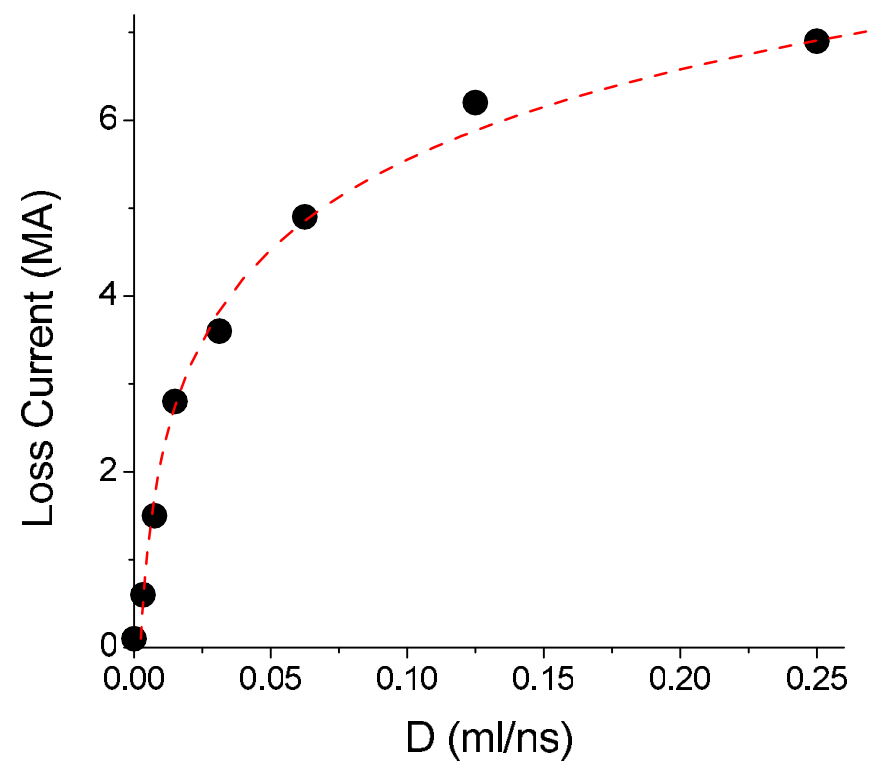

FIG. 4. (Color) Loss current values (circles) plotted as a function of cathode plasma desorption rate $D$ from the PIC simulations. The dashed line is a logarithmic function fit discussed in the text.
One likely path for plasma expansion across the AK gaps in the convolute region is along magnetic field nulls. The locations of these nulls are illustrated in Fig. 5 in the $\theta=0$ and 15 degree planes. These nulls intersect the anode at regions discussed in Sec. I, where material damage is observed on the actual $Z$ hardware. Figure 6 plots the charged-particle densities in the $\theta=0$ plane at $120 \mathrm{~ns}$ for case $4 \mathrm{~F}$. The electron density, $n_{e}$, is plotted in Fig. 6(a), the (cathode-emitted) plasma ion density, $n_{\mathrm{pi}}$, is plotted in 6(b), and the density of the ions emitted from the anode post, $n_{\text {ai }}$, are plotted in 6(c). It has long been recognized that the magnetic field nulls in Fig. 5 provide a path for significant electron current losses in the convolute and this

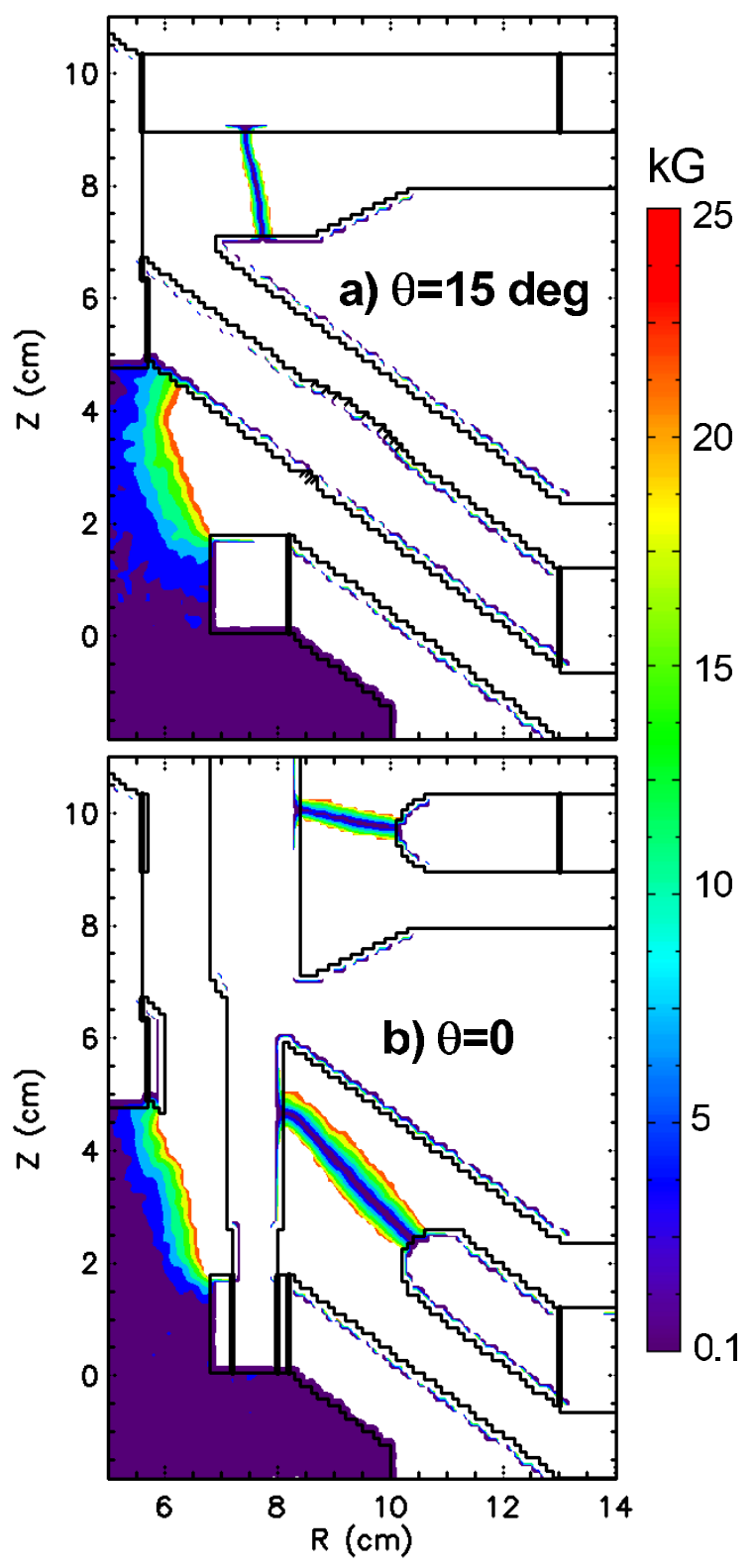

FIG. 5. (Color) Magnetic field magnitude in the (a) $\theta=15$ degree and (b) $\theta=0$ planes illustrating the location of the magnetic field nulls. 


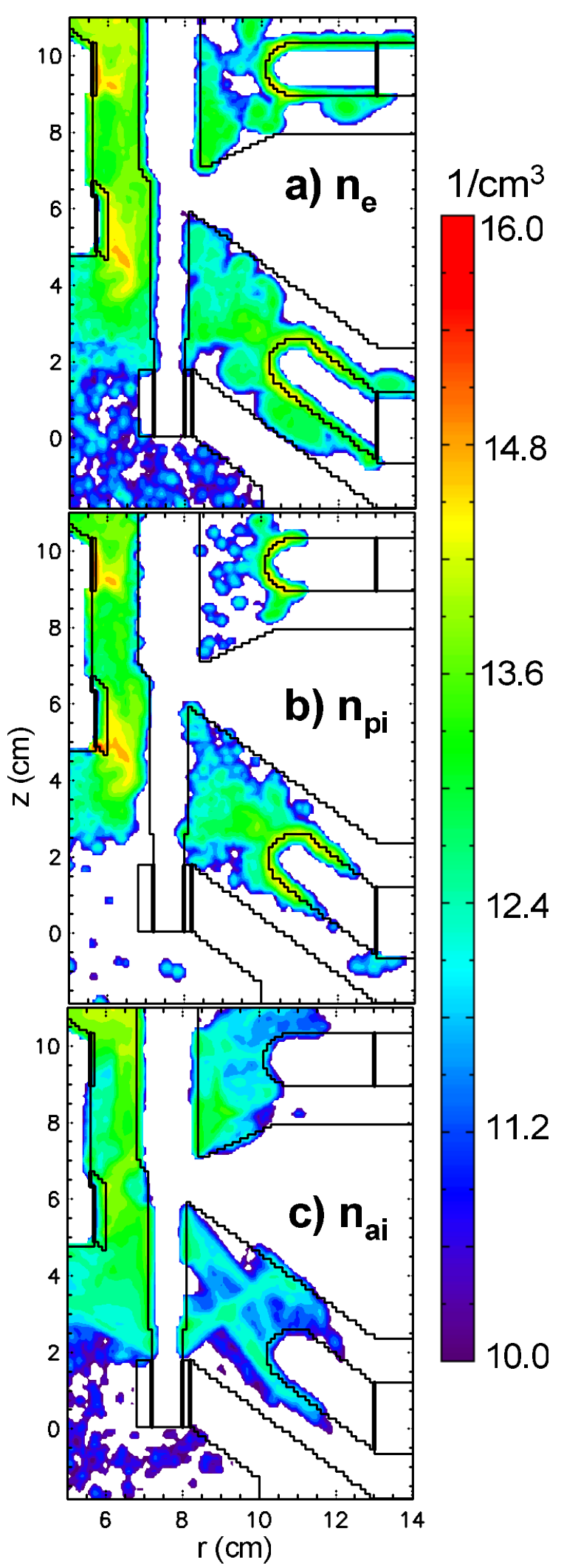

FIG. 6. (Color) Logarithmic-scale density contours in the $\theta=0$ plane at $120 \mathrm{~ns}$ for the simulation (with $D=0.0075 \mathrm{ml} / \mathrm{ns}$, case 4F); (a) electron density, (b) cathode-emitted plasma ions, and (c) the anode-emitted ions. was clearly demonstrated in Refs. [1-4]. The effect of these field nulls as electron current loss channels is magnified in the presence of cathode plasma injection, as illustrated in Fig. 6. Indeed, significant electron density, shown in Fig. 6(a), is present along the nulls. Note that the plasma ion density contours extend into the regions between the cathode plate "holes" and the anode posts, bringing the effective cathode (the leading edge of the dense plasma) to increasingly closer proximity of the anode. This significantly affects the operating impedance of the convolute, increasing the loss currents in this region by an order of magnitude relative to the electron emission case. [Although not shown in Fig. 6, the plasma penetration effects discussed above for the magnetic nulls at $\theta=0$ are also observed at the magnetic nulls that form at the periodic boundaries $(\theta= \pm 15$ degrees $)$ between the posts.]

In addition to enhanced current losses along the magnetic field nulls, expansion of cathode plasma across the magnetized vacuum downstream of the posts is observed in Fig. 6. Here, dense $\left(n_{\mathrm{pi}}>10^{14} \mathrm{~cm}^{-3}\right)$ plasma extends from the cathode to within a few millimeters of the anode posts. This penetration provides a significant current loss region in these simulations. The rapid penetration of the low density plasma into the magnetic field is consistent with observations and models of other plasma devices, such as plasma opening switches (e.g., Ref. [44]).

The anode-emitted ions [Fig. 6(c)] do not reach peak densities comparable to the cathode plasma ion densities on these time scales, but they are more energetic. Aided by the evolving cathode plasmas, the SCL emission ions cross the AK gap along the paths established by the magnetic nulls and other regions. Although not modeled here, these energetic ions striking the cathode would likely enhance the plasma production rate at the cathode through heating and stimulated desorption processes. These coupled processes have been successfully modeled in high-power electron-beam diodes [20], and such modeling techniques will be applied in future simulations as more detailed shotby-shot comparisons with the $Z$ shot database are carried out.

One way to visualize the enhanced losses due to cathode plasma evolution is shown in Figs. 7 and 8 which plot the electron energy deposition on the surface of different sections of the anode structures. Both frames in Fig. 7 are views of the energy deposited on the upper and lower posts from case $4 \mathrm{~F}$ after $120 \mathrm{~ns}$. The posts in 7(a) are rotated to highlight the deposition on the downstream side and 7(b) highlights the deposition on the upstream side. The most striking evidence of enhanced electron loss is shown on the downstream side of both upper and lower posts. These positions are directly across from the high density plasma regions that penetrate into the $\sim 1$-cm AK gap in Fig. 6(b). The deposition on the upstream side of the posts, 7(b), coincide with the end of the magnetic nulls that connect the cathode plate (inner edge of the cathode hole) 


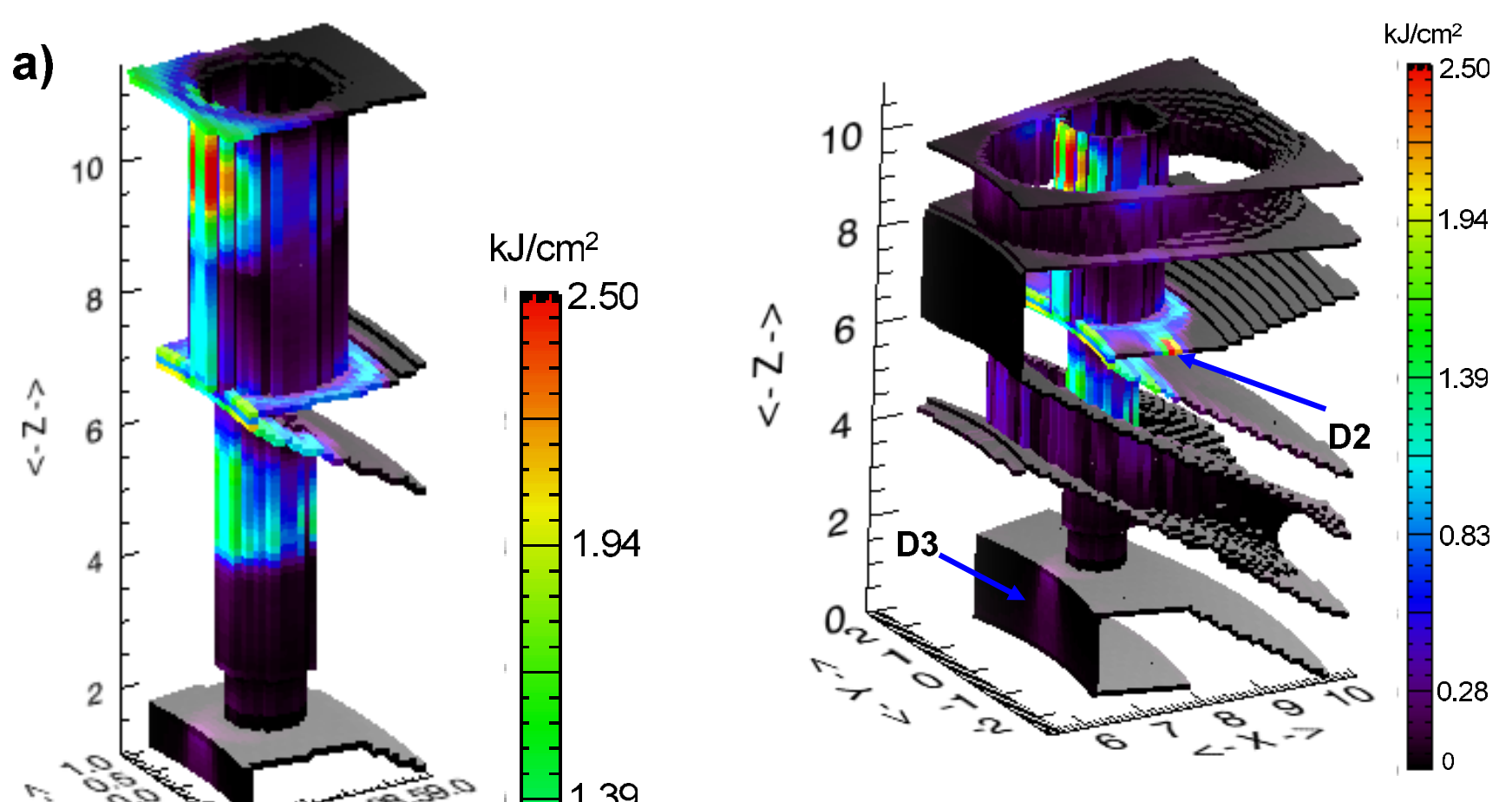

FIG. 8. (Color) Extended view of electron energy deposition on additional structures not shown in Fig. 7. Points labeled D2 and D3 are discussed in the text.

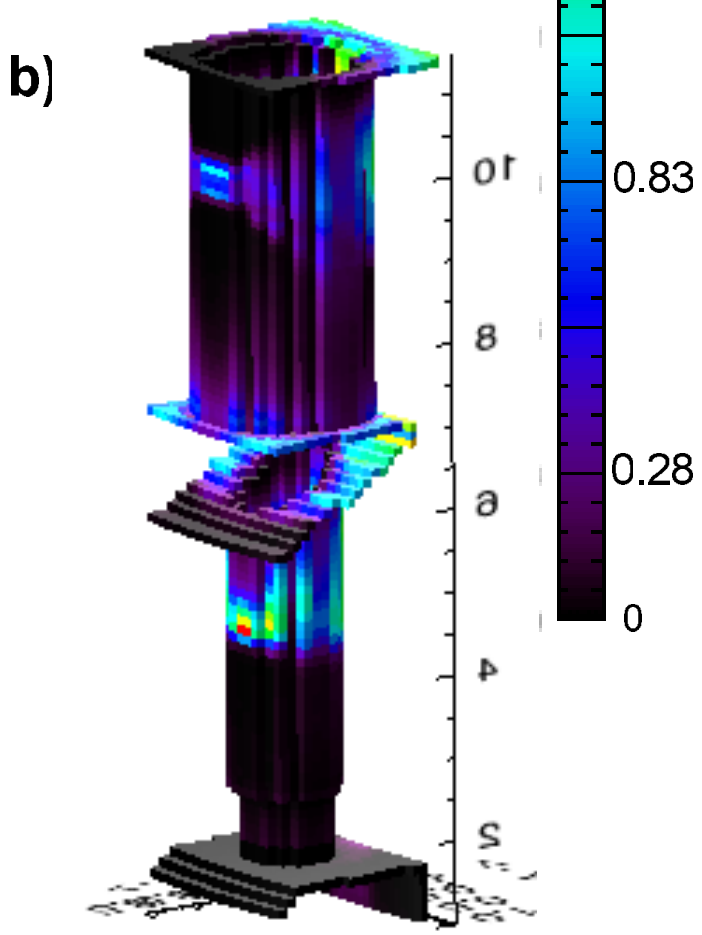

FIG. 7. (Color) Electron energy surface deposition on the anode posts after $120 \mathrm{~ns}$ for the plasma injection simulation $(D=$ $0.0075 \mathrm{ml} / \mathrm{ns}$, case $4 \mathrm{~F}$ ) with views highlighting (a) the downstream side of the posts and (b) the upstream side.

with the anode post. In addition, these deposition regions on the upstream and downstream sides of the posts are connected by extended regions of lower levels of deposited energy. This is due to energetic electrons drifting along magnetic field lines made accessible by the expanding cathode plasmas.

Figure 8 gives an additional view of the energy deposited in other regions discussed in Sec. I. Energy deposited near the base of the upper post (D2) represents losses due to the magnetic field null at the $\theta=15$ degree plane, while the extended region of enhanced energy deposition below this location is due to cathode plasma expansion at the outer edge of the cathode reducing the effective electron power flow gap in level "c". The location labeled D3 at the base of the lower post is also a region of electron energy deposition observed in previous simulations. These regions of energy deposition found in the simulations are consistent with anode damage routinely observed in the $Z$ convolute hardware.

\section{DISCUSSION AND CONCLUSIONS}

The computational modeling presented here represents the first estimates of current losses in a post-hole convolute system due to the formation and dynamics of cathode plasmas. For the first time, numerical simulations have given current loss magnitudes consistent with observations from the $Z$ machine operated at 18.5 MA. These compelling results are the first steps in a planned, larger effort to model current losses on an individual, shot-by-shot basis for $Z$ and $Z R[8,45]$.

From the comparisons with experiment, we have identified a range of plasma desorption rates that are consistent 
with surface contaminant inventories between 10 and 50 monolayers required for sustained cathode plasma formation throughout the duration of the $Z$ power pulse $[46,47]$. The trends observed in our recent high-power electronbeam diode simulations [20] suggest that cathode plasma injection rates should be roughly consistent with densities required for extraction of Child-Langmuir currents. The simulations presented here suggest significantly lower plasma injection rates resulting in current losses that are consistent with measured $Z$ losses.

The modeling presented here will be further extended to include ion emission from addition anode components, which has been examined in previous studies of electron power flow in DPH convolutes [1-4]. Electron energy deposition levels at anode component locations other than the posts exceed the threshold levels associated with ion emission. In addition, a model tracking the resistive heating of conductors within the PIC code has been developed. This model adds yet another mechanism to determine the onset of ion or plasma emission in a selfconsistent way. Similar models have been applied to the study of other high current coaxial transmission lines, e.g., Refs. [48,49]. These studies will be part of an ongoing effort to obtain a comprehensive model of post-hole convolutes used in high-power transmission-line systems.

\section{ACKNOWLEDGMENTS}

The authors thank C. Mostrom, Voss Scientific, for assistance with all of the simulations and data analysis presented here. The simulations were carried out on large-scale parallel computer systems at Voss Scientific and Sandia National Laboratories. The authors thank all of the systems support staff for their outstanding efforts to complete these simulations. This work was supported by Sandia National Laboratories. Sandia is a multiprogram laboratory operated by Sandia Corporation, a Lockheed Martin Company, for the United States Department of Energy's National Nuclear Security Administration under Contract No. DE-AC04-94-AL85000.

\section{APPENDIX: TRANSMISSION-LINE DRIVER CIRCUITS AND LOAD MODEL}

Each of the four input levels (labeled "a" through "d" in Fig. 2) are driven by transmission-line circuits that approximately model the voltage wave transmission along the parallel-plate MITL sections upstream of the convolute region. The forward-going wave used as input to these transmission lines is shown in Fig. 9. This voltage waveform was determined from circuit simulations modeling the $Z$ pulse forming line upstream of the convolute and load regions. The transmission-line configurations for the four levels are shown in Fig. 10. The forward-going voltage waveform from Fig. 9 is input at the left-hand side of each transmission-line circuit, and the arrow at the right-hand

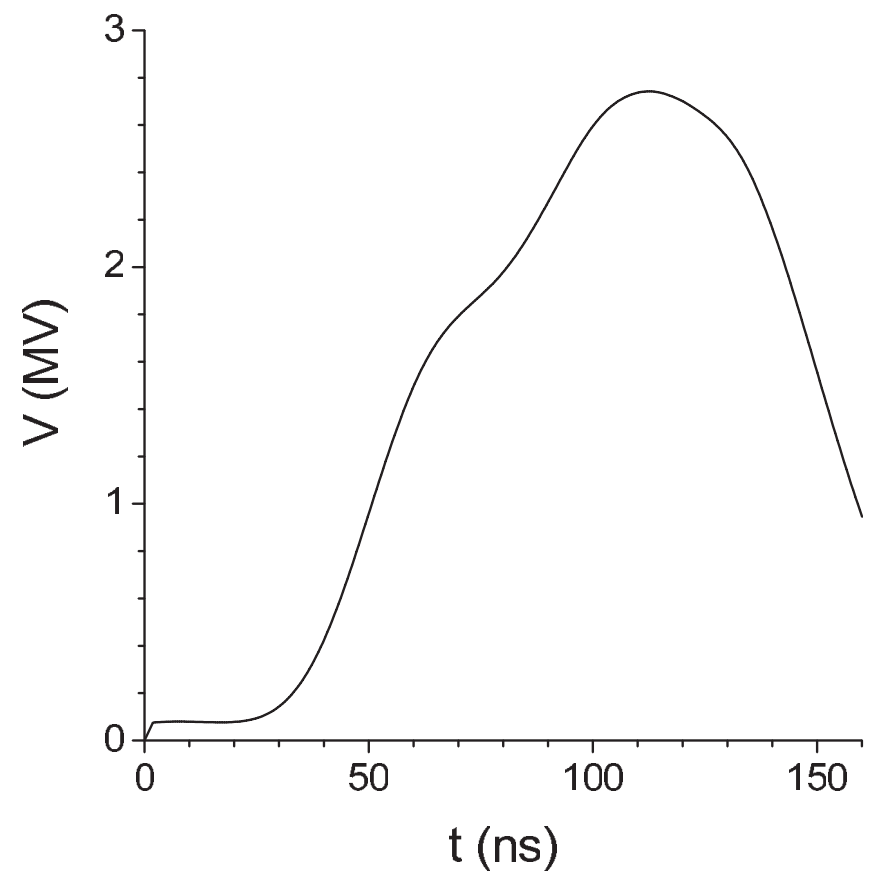

FIG. 9. Forward-going voltage waveform used to drive the transmission-line circuits.

side of each circuit indicates the connection to the simulation grid at the appropriate level.

The $z$-pinch load is modeled as an idealized cylindrical imploding liner, where an annular mass of length $L$ is driven radially inward by the force associated with the azimuthal magnetic field generated by the current $I_{L}$ flowing in the specified annular mass (see Fig. 11 for a schematic). The implosion is terminated at a specified final radius. A time-dependent inductance is calculated from the model

$$
L_{L}(t) \propto L \ln [R / r(t)],
$$

where $R$ is the radius of the fixed conductor containing the $z$-pinch, and $r(t)$ is the time-dependent load radius. The load voltage is then

\section{a) Levels "a" and "b"}

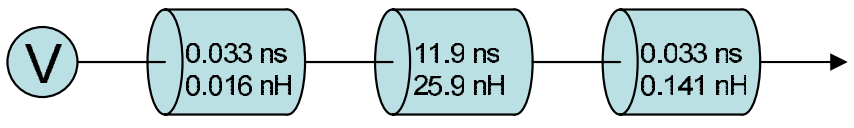

b) Levels " $c$ " and " $d$ "

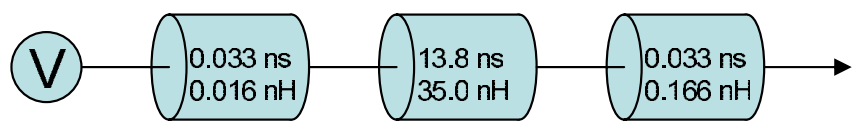

FIG. 10. (Color) Transmission-line models used to drive the four wave boundary inputs for the $2-\mathrm{cm}$ radius load simulations. The voltage waveform from Fig. 9 is input at the left and the arrow at the right indicates the connection to the simulation grid. 


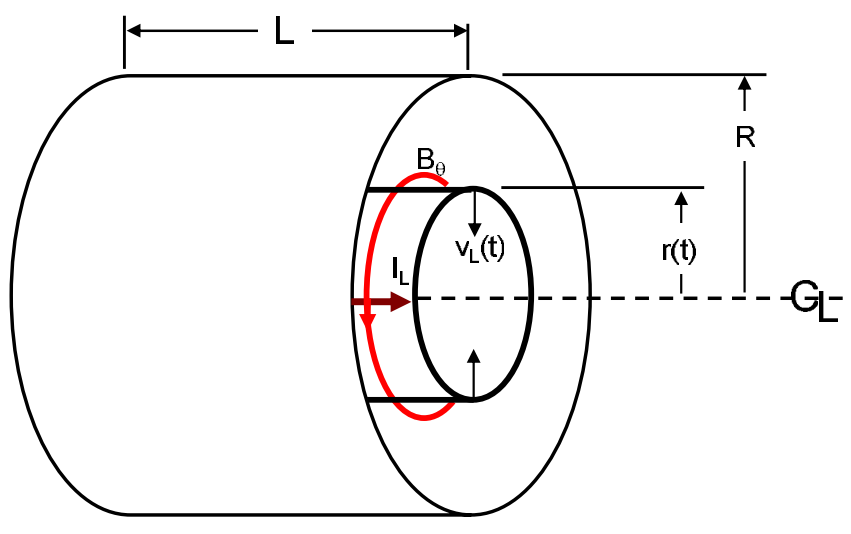

FIG. 11. (Color) Schematic of the imploding liner model used to model the time-dependent impedance of the $z$-pinch load. An azimuthal magnetic field $B_{\theta}$ is created by the current $I_{L}$ flowing in the liner. The magnetic field generates a force that accelerates the annular mass radially inward with time-dependent velocity $v_{L}$.

$$
V_{L}(t)=\frac{d}{d t}\left[L_{L}(t) I_{L}(t)\right]
$$

and this constitutes the reflected wave voltage due to the changing load impedance in the PIC simulation.

[1] T.P. Hughes and R.E. Clark, Mission Research Corp. Report No. MRC/ABQ-1875, 1998.

[2] T.P. Hughes and R.E. Clark, Mission Research Corp. Report No. MRC/ABQ-2005, 2000.

[3] T. P. Hughes, R. E. Clark, B. V. Oliver, R. A. St. John, and W. A. Stygar, Mission Research Corp. Report No. MRC/ ABQ-2066, 2002.

[4] T. D. Pointon, W. A. Stygar, R. B. Spielman, H. C. Ives, and K. W. Struve, Phys. Plasmas 8, 4534 (2001).

[5] C. W. Mendel, Jr., T.D. Pointon, M.E. Savage, D. B. Seidel, I. Magne, and R. Vezinet, Phys. Plasmas 13, 043105 (2006).

[6] T.D. Pointon, W.L. Langston, and M.E. Savage, Proceedings of the IEEE Pulsed Power Plasma Scientific Conference, edited by E. Schamiloglu and F. Peterkin (IEEE, Piscataway, NJ, 2007), p. 165.

[7] W. A. Stygar, M. E. Cuneo, D. I. Headley, H. C. Ives, R. J. Leeper, M. G. Mazarakis, C. L. Olson, J. L. Porter, and T. C. Wagoner, Phys. Rev. ST Accel. Beams 10, 030401 (2007).

[8] K. R. Matzen, Proceedings of the 2007 IEEE Pulsed Power and Plasma Science Conference, edited by E. Schamiloglu and F. Peterkin (IEEE, Piscataway, NJ, 2007), p. 1.

[9] R. B. Spielman, C. Deeney, G. A. Chandler, M. R. Douglas, D. L. Fehl, M. K. Matzen, D. H. McDaniel, T. J. Nash, J. L. Porter, and T. W. L. Sanford, Phys. Plasmas 5, 2105 (1998).

[10] R. B. Spielman, W. A. Stygar, J. F. Seamen, F. Long, H. Ives, R. Garcia, T. Wagoner, K. W. Struve, M. Mostrom, I. Smith, P. Spence, and P. Corcoran,
Proceedings of the 11th IEEE International Pulsed Power Conference, edited by G. Cooperstein and I. Vitkovitsky (IEEE, Piscataway, NJ, 1997), p. 709.

[11] P. A. Corcoran, J. W. Douglas, I. D. Smith, P. W. Spence, W. A. Stygar, K. W. Struve, T. H. Martin, R. B. Spielman, and H. C. Ives, Proceedings of the 11th IEEE International Pulsed Power Conference, Ref. [10], p. 466.

[12] H. C. Ives, D. M. Van De Valde, F. W. Long, J. W. Smith, R. B. Spielman, W. A. Stygar, R. W. Wavrik, and R. W. Shoup, Proceedings of the 11th IEEE International Pulsed Power Conference, Ref. [10], p. 1602.

[13] W. A. Stygar, R. B. Spielman, G. O. Allshouse, C. Deeney, D. R. Humphreys, H. C. Ives, F. W. Long, T. H. Martin, M. K. Matzen, D. H. McDaniel, C. W. Mendel, Jr., L. P. Mix, T. J. Nash, J. W. Poukey, J.J. Ramirez, T. W. L. Sanford, J. F. Seamen, D. B. Seidel, J. W. Smith, D. M. Van De Valde, R. W. Wavrik, P. A. Corcoran, J. W. Douglas, I. D. Smith, M. A. Mostrom, K. W. Struve, T. P. Hughes, R. E. Clark, R. W. Shoup, T.C. Wagoner, T. L. Gilliland, and B. P. Peyton, Proceedings of the 11th IEEE International Pulsed Power Conference, Ref. [10], p. 591.

[14] W. A. Stygar, H. C. Ives, D. L. Fehl, M. E. Cuneo, M. G. Mazarakis, J. E. Bailey, G. R. Bennett, D. E. Bliss, G. A. Chandler, R. J. Leeper, M. K. Matzen, D. H. McDaniel, J. S. McGurn, J. L. McKenney, L. P. Mix, D. J. Muron, J. L. Porter, J. J. Ramirez, L. E. Ruggles, J. F. Seamen, W. W. Simpson, C. S. Speas, R. B. Spielman, K. W. Struve, J. A. Torres, and R. A. Vesey, Phys. Rev. E 69, 046403 (2004).

[15] R. W. Stinnet and T. Stanley, J. Appl. Phys. 53, 3819 (1982).

[16] R. W. Stinnet, M. A. Palmer, R. B. Spielman, and R. Bengtson, IEEE Trans. Plasma Sci. 11, 216 (1983).

[17] R. Presura, B. S. Bauer, A. Esaulov, S. Fuelling, V. Ivanov, N. Le Galloudec, V. Makhin, R. E. Siemon, V. I. Sotnikov, R. Wirtz, A. Astanovitsky, S. Batie, H. Faretto, B. Le Galloudec, A. Oxner, M. Angelova, P. Laca, S. Guzzetta, S. Keely, and S. Rogowski, Proceedings of the 2003 Pulsed Power Conference, edited by M. Giesselmann and A. Neuber (IEEE, Piscataway, NJ, 2003), p. 859.

[18] V. V. Ivanov, P. J. Laca, B.S. Bauer, R. Presura, V. I. Sotnikov, A.L. Astanovitskiy, B. Le Galloudec, J. Glassman, and R. A. Wirtz, IEEE Trans. Plasma Sci. 32, 1843 (2004).

[19] Y. L. Bakshaev, A. V. Bartov, P. I. Blinov, A. S. Chernenko, S. A. Dan'ko, Y. G. Kalinin, A. S. Kingsep, V. D. Korolev, V. I. Mizhiritskii, V.P. Smirnov, A. Yu. Shashkov, P. V. Sasorov, and S. I. Tkachenko, Plasma Phys. Rep. 33, 259 (2007).

[20] D. R. Welch, D. V. Rose, N. Bruner, S. Portillo, and B. V. Oliver, Proceedings of the 2007 IEEE Pulsed Power and Plasma Science Conference, Ref. [8], p. 966.

[21] D. R. Welch, D. V. Rose, M.E. Cuneo, R. B. Campbell, and T. A. Mehlhorn, Phys. Plasmas 13, 063105 (2006).

[22] LSP is a software product developed by ATK Mission Research, Albuquerque, NM 87110, with initial support from the Department of Energy SBIR Program.

[23] D. R. Welch, D. V. Rose, B. V. Oliver, and R. E. Clark, Nucl. Instrum. Methods Phys. Res., Sect. A 464, 134 (2001).

[24] D. R. Welch, D. V. Rose, R.E. Clark, T.C. Genoni, and T. P. Hughes, Comput. Phys. Commun. 164, 183 (2004). 
[25] C. K. Birdsall and A. B. Langdon, Plasma Physics via Computer Simulation (Adam Hilger, New York, 1991).

[26] T. C. Genoni, D. V. Rose, D. R. Welch, and E. P. Lee, Phys. Plasmas 11, L73 (2004).

[27] D. V. Rose, T. C. Genoni, D. R. Welch, and E. P. Lee, Nucl. Instrum. Methods Phys. Res., Sect. A 544, 389 (2005).

[28] D. V. Rose, J. U. Guillory, and J. H. Beall, Phys. Plasmas 9 , 1000 (2002).

[29] D. V. Rose, T. C. Genoni, D. R. Welch, E. A. Startsev, and R. C. Davidson, Phys. Rev. ST Accel. Beams 10, 034203 (2007).

[30] D. V. Rose, J. Guillory, and J. H. Beall, Phys. Plasmas 12, 014501 (2005).

[31] D. V. Rose, T. C. Genoni, D. R. Welch, T. A. Mehlhorn, J. L. Porter, and T. Ditmire, Phys. Plasmas 13, 092507 (2006).

[32] D. R. Welch, T. C. Genoni, R. E. Clark, and D. V. Rose, J. Comput. Phys. 227, 143 (2007).

[33] http://www.dell.com

[34] http://www.intel.com

[35] http://www.infinibandta.org

[36] M. S. DiCapua and D. G. Pellinen, J. Appl. Phys. 50, 3713 (1979).

[37] R.E. Shefer, L. Friedland, and R. E. Klinkowstein, Phys. Fluids 31, 930 (1988).

[38] D. R. Welch, D. V. Rose, N. Bruner, S. Portillo, and B. V. Oliver (to be published).

[39] A.E. Blaugrund, G. Cooperstein, and S. A. Goldstein, Phys. Fluids 20, 1185 (1977).

[40] T. W. L. Sanford, J.A. Halbleib, J. W. Poukey, A. L. Pregenzer, R.C. Pate, C.E. Heath, R. Mock, G. A.
Mastin, D.C. Ghiglia, T. J. Roemer, P. W. Spence, and G. A. Proulx, J. Appl. Phys. 66, 10 (1989).

[41] G. Cooperstein, J. R. Boller, R. J. Commisso, D. D. Hinshelwood, D. Mosher, P. F. Ottinger, J. W. Schumer, S. J. Stephanakis, S. B. Swanekamp, B. V. Weber, and F. C. Young, Phys. Plasmas 8, 4618 (2001).

[42] D. J. Johnson, J. P. Quintenz, and M. A. Sweeney, J. Appl. Phys. 57, 794 (1985).

[43] H. J. Bluhm, H. P. Laqua, L. Buth, P. J. W. Hoppe, and D. Rusch, IEEE Trans. Plasma Sci. 21, 560 (1993).

[44] J. J. Moschella, C. C. Klepper, C. Vidoli, E. J. Yadlowsky, B. V. Weber, R. J. Commisso, D. C. Black, B. Moosman, S. J. Stephanakis, D. D. Hinshelwood, and Y. Maron, Phys. Plasmas 12, 023102 (2005).

[45] E. A. Weinbrecht, D. D. Bloomquist, D. H. McDaniel, D. A. Tabor, J. W. Weed, T. V. Faturos, G. R. McKee, and P. J. Warner, Proceedings of the 2005 IEEE Pulsed Power Conference, edited by J. Maenchen and E. Schamiloglu (IEEE, Piscataway, NJ, 2005), p. 170.

[46] M.E. Cuneo, P. R. Menge, D. L. Hanson, W. E. Fowler, M. A. Bernard, G. R. Ziska, A. B. Filuk, T.D. Pointon, R. A. Vesey, D. R. Welch, J.E. Bailey, M.P. Dejarlais, T. R. Lockner, T. A. Mehlhorn, S.A. Slutz, and M. A. Stark, IEEE Trans. Plasma Sci. 25, 229 (1997).

[47] M.E. Cuneo, IEEE Trans. Dielectr. Electr. Insul. 6, 469 (1999).

[48] J. W. Schumer, P. F. Ottinger, and C. L. Olson, IEEE Trans. Plasma Sci. 34, 2652 (2006).

[49] P. F. Ottinger and J. W. Schumer, IEEE Trans. Plasma Sci. 35, 154 (2007). 